\title{
Aspectos de biologia floral de cajueiros anão precoce e comum
}

\author{
Floral biology aspects of the early dwarf and common cashew
}

\author{
Larissa Barbosa de Sousa ${ }^{\mathrm{I}}$ Lidiane de Lima FeitozaII Regina Lucia Ferreira Gomes ${ }^{\mathrm{III}}$ \\ Ângela Celis de Almeida Lopes ${ }^{\text {IV }}$ Edson Basílio Soares ${ }^{\text {III }}$ \\ Eduardo Magno Pereira da Silva ${ }^{I}$
}

\begin{abstract}
O conhecimento da biologia floral é de suma importância para o desenvolvimento da cultura do cajueiro (Anacardium occidentale L.). Com relação aos aspectos botânicos, as características morfológicas das flores contribuíram efetivamente para a determinação das espécies do gênero Anacarduim conhecidas. No presente trabalho, objetivou-se estudar a biologia floral dos cajueiros anão precoce e comum. A pesquisa foi desenvolvida na área experimental do Departamento de Fitotecnia, Centro de Ciências Agrárias, Universidade Federal do Piauí, em Teresina, PI, avaliando-se nove clones de cajueiro anão ("CAP 14", "Embrapa 09", “Embrapa 50”, "Embrapa 51”, “Embrapa 76”, "Embrapa 183”, "Embrapa 189”, "FAGA 01", "FAGA 11”) e um clone de cajueiro comum ("CCA”), utilizando-se quatro panículas por planta, cada uma com orientação norte, sul, leste e oeste. Os tipos varietais, cajueiro comum e anão precoce, apresentam pouca variação para a maioria dos caracteres avaliados. A proporção entre flores hermafroditas e o total de flores, em cajueiro comum, pode levá-lo a uma maior produção de frutos por panícula do que nos clones de cajueiro anão precoce analisados. O número de frutos desenvolvidos é bastante reduzido nos dois tipos varietais. As panículas situadas em diferentes orientações cardeais são semelhantes em todos os clones estudados quanto aos aspectos relacionados à biologia floral do cajueiro.
\end{abstract}

- NOTA-

\section{ABSTRACT}

Palavras-chave: Anacardium occidentale, biologia floral, produção de frutos.

\begin{abstract}
The knowledge of the floral biology is very important for the development of the cashew's culture (Anacardium occidentale L.). In relation to botanical aspects, the morphological characteristics of flowers contributed effective to determination of the well-known species of Anacardium. It was aimed at studing the floral biology of the early dwarf and common cashew. The research was developed in the experimental area of the Department of Fitotecnia, Centro de Ciências Agrárias, Universidade Federal do Piauí, in Teresina, $P I$, and nine clones of dwarf cajueiro ('CAP 14', 'Embrapa 09', 'Embrapa 50', 'Embrapa 51', 'Embrapa 76', 'Embrapa 183', 'Embrapa 189', 'FAGA 01', 'FAGA 11') and a clone of common cashew ('CCA'), were evaluated using four paniculae per plant, in north, south, east and west orientation. The varietal types, common and early dwarf cashew, present little variation for most of the evaluated characteristics. The common cashew presents a larger proportion between the number of hermaphrodite flowers and the total number of flowers than the early dwarf cashew clones; this may facilitate a larger production of fruits in the common cashew. The number of developed fruits is very low in both varietal types. The paniculae placed in different cardinal orientations are similar in all the clones in relation to the aspects related to the floral biology of the cashew.
\end{abstract}

Key words: Anacardium occidentale, floral biology, fruits yield.

O cajueiro, Anacardium occidentale L., única espécie cultivada e a mais dispersa do gênero

\footnotetext{
ICurso de Engenharia Agronômica, Centro de Ciências Agrárias (CCA), Universidade Federal do Piauí (UFPI), Campus Ministro Petrônio Portela, Bairro Ininga, 64049-550, Teresina, PI, Brasil.

IICurso de Ciências Biológicas, Centro de Ciências da Natureza (CCN), UFPI, Teresina, PI, Brasil.

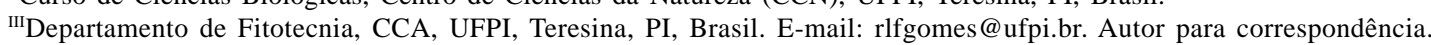

${ }^{\mathrm{IV}}$ Departamento de Biologia, CCN, UFPI, Teresina, PI, Brasil.
} 
(BARROS et al., 2002), pertence à família Anacardiaceae, que compreende cerca de 60 a 70 gêneros e 400 a 600 espécies (BARROS, 1993). O principal centro de diversidade do gênero Anacardium é a região Amazônica, com um centro secundário de diversidade nos cerrados, no Planalto Central. Contudo, a maior diversidade de Anacardium occidentale L. encontrase no Nordeste brasileiro (CRISÓSTOMO et al., 2002), região responsável por cerca de $94 \%$ da produção de caju, principalmente nos Estados do Ceará, Piauí e Rio Grande do Norte, nas faixas litorânea e de transição com outros ecossistemas. O fato de esses estados serem os intensamente afetados pelas alterações climáticas periódicas (secas) que ocorrem na região permite inferir pela ampla adaptabilidade da espécie nos diversos ecossistemas.

A falta de tecnologia para o cultivo do cajueiro deve-se a vários fatores, incluindo pequeno número de pesquisadores, limitação de recursos para pesquisa e a própria natureza da cultura. É uma planta perene, com período de frutificação prolongado, com a qual a experimentação usualmente é trabalhosa e complicada (SILVA et al., 1998). Portanto, é compreensível que, mesmo aspectos básicos como a biologia floral, ainda necessitem de mais estudos.

O estudo da biologia floral do cajueiro é de suma importância, especialmente no que se refere aos aspectos botânicos e de melhoramento genético. As características morfológicas das flores contribuíram de modo efetivo para a determinação das espécies do gênero Anarcadium conhecidas (BARROS, 1988). Tais estudos, que permitem conhecer melhor a cultura nos seus aspectos morfológicos e fenológicos e determinar técnicas experimentais e análises estatísticas mais apropriadas à sua pesquisa, auxiliam na condução dos programas de melhoramento e no correto manejo da cultura, estabelecendo tecnologias adequadas à obtenção de maiores rendimentos. Nesse sentido, objetivou-se realizar o estudo da biologia floral de cajueiros anão precoce e comum.

O trabalho foi desenvolvido na área experimental do Departamento de Fitotecnia, do Centro de Ciências Agrárias, da Universidade Federal do Piauí, no município de Teresina, PI, situado a 5² $5^{\circ}$ de latitude sul, $42^{\circ} 29^{\prime}$ de longitude oeste e altitude de $72 \mathrm{~m}$, no período de 13 de julho de 2004 a 03 de dezembro de 2004. Utilizou-se um clone de cajueiro comum (“CCA”) e nove clones de cajueiro anão precoce (“CAP 14", “Embrapa 09”, “Embrapa 50”, “Embrapa 51”, “Embrapa 76”, “Embrapa 183”, “Embrapa 189”, “FAGA01”, “FAGA 11 ”), sendo avaliadas quatro plantas por clone e quatro panículas por planta, cada uma com orientação nos quatro pontos cardeais, correspondendo a um total de
16 panículas por clone. Os caracteres avaliados em cada panícula foram os seguintes: período de florescimento - número de dias compreendidos entre a abertura da primeira até a última flor; comprimento da panícula medida em centímetros, do nó até a extremidade do raquis; número de ramificações; números de flores masculinas e hermafroditas - avaliados mediante contagem diária desde o surgimento da primeira até a última flor; número total de flores; índice de sexualidade I - relação entre o número de flores masculinas e o número de flores hermafroditas; índice de sexualidade II - relação entre o número de flores hermafroditas e o número total de flores; número de frutos formados e número de frutos desenvolvidos. As análises estatísticas foram realizadas com o auxílio do programa GENES (Cruz, 2001), utilizando-se o delineamento inteiramente casualizado, sendo consideradas como repetições as quatro panículas de cada clone com a mesma orientação nos pontos cardeais.

Os tipos varietais de cajueiro diferiram com relação aos caracteres: comprimento da panícula, número de flores masculinas, número total de flores e índices de sexualidade I e II (Tabela 1). No cajueiro anão precoce, verificou-se maior comprimento de panícula, confirmando resultados encontrados por PINHEIRO \& PARENTE (1977). O cajueiro comum apresentou menor número de flores masculinas, conseqüentemente, menor índice de sexualidade I e maior índice de sexualidade II. Resultados semelhantes foram obtidos por PINHEIRO \& PARENTE (1977). Em estudos realizados em Pacajus, CE, no cajueiro anão precoce, foram registradas cerca de 201,9 flores por panícula, das quais apenas 3,9\% foram hermafroditas; no cajueiro comum, das 173,8 flores por panícula, 7,9\% foram hermafroditas (BARROS et al., 2002). O número de frutos desenvolvidos foi bastante reduzido no dois tipos varietais. SILVA et al. (1998) observaram variação de um a seis frutos por panícula, em cajueiro anão precoce, clone “CCP-006”. BARROS et al. (2002) encontraram percentagens de frutos formados que alcançaram o período de colheita de $9,9 \%$ e 10,3\%, em cajueiro comum e anão precoce, respectivamente.

As panículas situadas em diferentes orientações cardeais não diferiram quanto aos caracteres avaliados (Tabela 2). CRISÓSTOMO et al. (1992) observaram que 31\% da produção de castanha foi produzida no lado oeste e $29 \%$ no lado norte da copa da planta, enquanto nos lados leste e sul a produção foi de 21 e 19\%, respectivamente. Com base nesses resultados, recomendaram orientação e arranjo adequados de plantas.

Os clones de cajueiro comum e anão precoce não diferiram apenas com relação ao índice de 
Tabela 1 - Médias $^{1}$ e amplitudes de variação dos caracteres: período de florescimento, comprimento da panícula, número de ramificações/panícula, números de flores masculinas e hermafroditas/panícula, número total de flores/panícula, índice de sexualidade I, índice de sexualidade II, número de frutos formados/panícula e número de frutos desenvolvidos/panícula, avaliados nos tipos varietais de cajueiro, comum e anão precoce, em Teresina, PI, 2004.

\begin{tabular}{|c|c|c|c|c|}
\hline \multirow{3}{*}{ Caracteres } & \multicolumn{4}{|c|}{ Tipos varietais } \\
\hline & \multicolumn{2}{|c|}{ Cajueiro anão precoce } & \multicolumn{2}{|c|}{ Cajueiro comum } \\
\hline & Média² & Amplitude de variação & Média ${ }^{3}$ & Amplitude de variação \\
\hline Período de florescimento (dias) & 93,60 a & $39-125$ & 87,31 a & $48-180$ \\
\hline Comprimento da panícula (cm) & 16,75 a & $6,00-29,00$ & $11,03 \mathrm{~b}$ & $7,00-15,50$ \\
\hline $\mathrm{N}^{\circ}$ de ramificações/panícula & $7,90 \mathrm{a}$ & $2-13$ & $7,31 \mathrm{a}$ & $4-12$ \\
\hline $\mathrm{N}^{\mathrm{o}}$ de flores masculinas/panícula & $416,45 \mathrm{a}$ & $109-787$ & $243,50 \mathrm{~b}$ & $33-512$ \\
\hline $\mathrm{N}^{\circ}$ de flores hermafroditas/panícula & 30,50 a & $5-116$ & 31,94 a & $0-106$ \\
\hline $\mathrm{N}^{\circ}$ total de flores/panícula & $446,95 \mathrm{a}$ & $131-744$ & $274,81 \mathrm{~b}$ & $41-618$ \\
\hline Índice de sexualidade I & 18,76 a & $2,85-109,40$ & $9,42 \mathrm{~b}$ & $0-21,36$ \\
\hline Índice de sexualidade II & $0,07 \mathrm{~b}$ & $0,01-0,24$ & $0,21 \mathrm{a}$ & $0,05-1,86$ \\
\hline $\mathrm{N}^{\circ}$ de frutos formados/panícula & 2,98 a & $1-17$ & $1,94 \mathrm{a}$ & $0-5$ \\
\hline $\mathrm{N}^{\circ}$ de frutos desenvolvidos/panícula & 0,10 a & $0-1$ & 0,06 a & $0-1$ \\
\hline
\end{tabular}

${ }^{1}$ Médias seguidas de letras iguais, na mesma linha, não diferem entre si pelo teste Duncan $(\mathrm{P}<0,05)$.

${ }^{2}$ Média de 144 contagens realizadas em quatro panículas por planta, em quatro plantas de cada um dos nove clones de cajueiro anão precoce. ${ }^{3}$ Média de 16 contagens realizadas em quatro panículas por planta, sendo quatro plantas de um clone de cajueiro comum.

Índice de sexualidade I: relação entre o número de flores masculinas/número de flores hermafroditas; Índice de sexualidade II: relação entre o número de flores hermafroditas/número total de flores.

sexualidade II (Tabela 3). Considerado o número de flores masculinas, o número total de flores e o índice de sexualidade I, "Embrapa 50” destacou-se em relação a “CCA”, “Embrapa 09”, “Embrapa 189”, “Embrapa 51”, "FAGA11”, "FAGA 1” e “Embrapa 76”. O maior número de flores hermafroditas foi apresentado pelo clone “Embrapa 51”. Para o comprimento da panícula, "FAGA
1”, “Embrapa 76”, “Embrapa 50” e "FAGA 11” foram superiores a "Embrapa 51”, “Embrapa 189” e "CCA”, sendo intermediários aos demais. "Embrapa 76" apresentou o maior número de ramificações por panícula. Quanto à duração de florescimento da panícula, os clones “CAP 14”, "FAGA 11”, “Embrapa 183”, “Embrapa 50”, “Embrapa 76”, “Embrapa 09” e

Tabela 2 - Médias ${ }^{1}$ dos caracteres: período de florescimento, comprimento da panícula, número de ramificações/panícula, números de flores masculinas e hermafroditas/panícula, número total de flores/panícula, índice de sexualidade I, índice de sexualidade II, número de frutos formados/panícula e número de frutos desenvolvidos/panícula, avaliados em panículas de clones de cajueiro comum e anão precoce, com orientações nos quatro pontos cardeais, em Teresina, PI, 2004.

\begin{tabular}{|c|c|c|c|c|}
\hline \multirow{2}{*}{ Caracteres } & \multicolumn{4}{|c|}{ Pontos cardeais } \\
\hline & Leste & Norte & Oeste & Sul \\
\hline Período de florescimento (dias) & 87,43 a & 99,57 a & $90,71 \mathrm{a}$ & $89,50 \mathrm{a}$ \\
\hline Comprimento da panícula (cm) & $14,75 \mathrm{a}$ & $14,86 \mathrm{a}$ & $15,96 \mathrm{a}$ & $14,89 \mathrm{a}$ \\
\hline No de ramificações/panícula & 7,36 a & 7,64 a & 8,29 a & 7,64 a \\
\hline $\mathrm{N}^{\circ}$ de flores masculinas/panícula & 393,00 a & $407,00 \mathrm{a}$ & 353,00 a & $315,00 \mathrm{a}$ \\
\hline $\mathrm{N}^{\circ}$ de flores hermafroditas/panícula & $31,00 \mathrm{a}$ & 33,00 a & $32,00 \mathrm{a}$ & $28,00 \mathrm{a}$ \\
\hline $\mathrm{N}^{\circ}$ total de flores/panícula & $424,00 \mathrm{a}$ & 439,00 a & 385,00 a & $343,00 \mathrm{a}$ \\
\hline Índice de sexualidade I & 19,90 a & $16,47 \mathrm{a}$ & $15,22 \mathrm{a}$ & 12,79 a \\
\hline Índice de sexualidade II & $0,20 \mathrm{a}$ & 0,07 a & 0,09 a & $0,08 \mathrm{a}$ \\
\hline $\mathrm{N}^{\mathrm{o}}$ de frutos formados/panícula & $3,00 \mathrm{a}$ & $4,00 \mathrm{a}$ & $2,00 \mathrm{a}$ & $1,00 \mathrm{a}$ \\
\hline $\mathrm{N}^{\circ}$ de frutos desenvolvidos/panícula & $1,00 \mathrm{a}$ & $1,00 \mathrm{a}$ & $0,00 \mathrm{a}$ & $0,00 \mathrm{a}$ \\
\hline
\end{tabular}

${ }^{1}$ Médias seguidas de letras iguais, na mesma linha, não diferem entre si pelo teste Duncan $(\mathrm{P}<0,05)$. Correspondem a 40 contagens realizadas em uma panícula por planta, em quatro plantas de cada um dos dez clones de cajueiro.

Índice de sexualidade I: relação entre o número de flores masculinas/número de flores hermafroditas; Índice de sexualidade II: relação entre o número de flores hermafroditas/número total de flores. 
Tabela 3 - Médias ${ }^{1}$ dos caracteres: números de flores masculinas e hermafroditas /panícula (NFM) e (NFH), número total de flores/panícula (NTF), índice de sexualidade I (IS I), índice de sexualidade II (IS II), período de florescimento (PF), comprimento da panícula (CP), número de ramificações/panícula (NR), número de frutos formados/panícula (NFF) e número de frutos desenvolvidos /panícula (NFD), avaliados nos clones de cajueiro comum e anão precoce, em Teresina, PI, 2004.

\begin{tabular}{|c|c|c|c|c|c|c|c|c|c|c|}
\hline \multirow{2}{*}{ Clones } & \multicolumn{10}{|c|}{ Caracteres } \\
\hline & NFM & $\mathrm{NFH}$ & NTF & ÍS I & ÍS II & PF (dias) & $\mathrm{CP}(\mathrm{cm})$ & NR & $\mathrm{NFF}$ & NFD \\
\hline “CCA" & $243,50 \mathrm{~d}$ & $31,94 b$ & $274,81 \mathrm{~d}$ & $9,42 \mathrm{c}$ & $0,21 \mathrm{a}$ & $87,31 \mathrm{a}$ & $11,03 \mathrm{~b}$ & $7,31 \mathrm{~cd}$ & $1,94 \mathrm{ab}$ & $0,06 \mathrm{~b}$ \\
\hline “CAP 14” & 430,63 abcd & $17,88 \mathrm{~b}$ & 448,50abcd & $28,28 \mathrm{ab}$ & $0,02 \mathrm{a}$ & $109,88 \mathrm{a}$ & $15,50 a b$ & $8,13 \mathrm{ab}$ & $1,25 b$ & $0,00 \mathrm{~b}$ \\
\hline “Embrapa 09” & 318,75 bcd & $31,75 \mathrm{~b}$ & 350,50 bcd & $13,82 \mathrm{c}$ & $0,08 \mathrm{a}$ & 99,50 a & $15,00 \mathrm{ab}$ & 7,75 bc & 4,50 ab & $0,25 a b$ \\
\hline “Embrapa 50” & $610,75 \mathrm{a}$ & $14,75 \mathrm{~b}$ & $625,50 \mathrm{a}$ & $31,56 \mathrm{a}$ & $0,02 \mathrm{a}$ & 104,25 a & $19,75 \mathrm{a}$ & $8,25 \mathrm{ab}$ & $1,25 \mathrm{~b}$ & $0,25 a b$ \\
\hline “Embrapa 51” & 427,25 abcd & 80,75 a & $508,00 \mathrm{abc}$ & $7,03 \mathrm{c}$ & $0,16 \mathrm{a}$ & $55,75 b$ & $13,50 \mathrm{~b}$ & 5,25 c & $3,75 \mathrm{ab}$ & $0,00 \mathrm{~b}$ \\
\hline “Embrapa 76” & 308,50 cd & $20,00 \mathrm{~b}$ & 328,50 cd & 17,61 bc & $0,04 \mathrm{a}$ & $103,50 \mathrm{a}$ & 20,00 a & $10,50 \mathrm{a}$ & 2,25 ab & $0,50 \mathrm{a}$ \\
\hline “Embrapa 183” & $473,50 \mathrm{abc}$ & $31,50 \mathrm{~b}$ & 505,25 abc & $18,53 a b c$ & $0,06 \mathrm{a}$ & 108,25 a & $16,00 \mathrm{ab}$ & $8,00 \mathrm{ab}$ & $2,00 a b$ & $0,00 \mathrm{~b}$ \\
\hline “Embrapa 189” & 290,75 cd & $20,50 \mathrm{~b}$ & $311,25 \mathrm{~cd}$ & 16,39 bc & $0,06 \mathrm{a}$ & $80,75 \mathrm{ab}$ & $13,25 b$ & $7,25 \mathrm{bc}$ & $3,00 \mathrm{ab}$ & $0,00 \mathrm{~b}$ \\
\hline “FAGA 1" & 357,00 bcd & $31,50 \mathrm{~b}$ & 388,50 bcd & 10,83 c & $0,10 \mathrm{a}$ & $55,50 \mathrm{~b}$ & $20,00 \mathrm{a}$ & $7,50 \mathrm{bc}$ & $6,50 \mathrm{a}$ & $0,00 \mathrm{~b}$ \\
\hline "FAGA 11" & $516,50 \mathrm{ab}$ & $38,50 \mathrm{~b}$ & $555,00 \mathrm{ab}$ & 15,29 bc & $0,07 \mathrm{a}$ & 108,75 a & $19,00 \mathrm{a}$ & $8,25 \mathrm{ab}$ & 4,00 ab & $0,00 \mathrm{~b}$ \\
\hline
\end{tabular}

${ }^{1}$ Médias seguidas de letras iguais, na mesma coluna, não diferem entre si pelo teste Duncan $(\mathrm{P}<0,05)$. Correspondem a 16 contagens realizadas em quatro panículas por planta, em quatro plantas de cada clone de cajueiro.

Índice de sexualidade I: relação entre o número de flores masculinas/número de flores hermafroditas; Índice de sexualidade II: relação entre o número de flores hermafroditas/número total de flores.

“CCA” suplantaram "Embrapa 51” e "FAGA 1". Para número de frutos formados, "FAGA 1" superou “Embrapa 50” e “CAP 14”, não diferindo significativamente dos demais. Quanto ao número de frutos desenvolvidos, “Embrapa 76” foi semelhante a “Embrapa 09” e “Embrapa 50”, e superior aos outros clones avaliados. O número de frutos desenvolvidos foi bastante reduzido em todos os clones avaliados. SILVA et al. (1998) observaram variação de um a seis frutos por panícula no clone “CCP-006”, de cajueiro anão precoce.

Os tipos varietais, cajueiro comum e anão precoce, apresentam pouca variação para a maioria dos caracteres avaliados. A proporção entre flores hermafroditas e o total de flores, em cajueiro comum, pode levá-lo a uma maior produção de frutos por panícula do que nos clones de cajueiro anão precoce analisados. O número de frutos desenvolvidos é bastante reduzido nos dois tipos varietais. As panículas situadas em diferentes orientações cardeais são semelhantes em todos os clones estudados quanto aos aspectos relacionados à biologia floral do cajueiro.

\section{AGRADECIMENTOS}

À Fundação de Amparo à Pesquisa do Estado do Piauí (FAPEPI) e ao Conselho Nacional de Desenvolvimento Científico e Tecnológico (CNPq), pelo apoio financeiro e pela concessão de bolsas de Iniciação Científica.

\section{REFERÊNCIAS}

BARROS, L.M. Biologia floral, colheita e rendimento. In: LIMA, V.P.M.S. A cultura do cajueiro no Nordeste do Brasil. Fortaleza: BNB/ETENE, 1988. p.301-319. (BNB/ ETENE. Estudos Econômicos e Sociais, 35).

BARROS, L.M. et al. Cajueiro. In: BRUCKNER, C.H. (Ed). Melhoramento de fruteiras tropicais. Viçosa: UFV, 2002. p.159-176.

BARROS, L.M. et al. Recomendações técnicas para a cultura do cajueiro anão precoce. Fortaleza: EMBRAPA/CNPAT, 1993. 65p. (EMBRAPA-CNPAT. Circular Técnica, 1).

CRISÓSTOMO, J.R. et al. Orientação para o plantio de cajueiro em relação aos pontos cardeais. Fortaleza: EMBRAPA/CNPAT, 1992. 2p. (Comunicado Técnico, 3).

CRISÓSTOMO, J.R. et al. Melhoramento do cajueiro-anãoprecoce: avaliação da qualidade do pedúnculo e a heterose dos seus híbridos. Revista Brasileira de Fruticultura, v.24, n.2, p.477-480, 2002.

CRUZ, C.D. Programa genes: aplicativo computacional em genética e estatística. Viçosa: UFV, 2001. 648p.

PINHEIRO, F.F.M; PARENTE, J.I.G. Estudos preliminares sobre a biologia floral do cajueiro (Anacardium occidentale L.), no Ceará. In: CONGRESSO BRASILEIRO DE FRUTICULTURA, 4., 1977, Salvador. Anais... Salvador: SBF, 1977. p.3.

SILVA, P.S.L. et al. Distribuição dos frutos no cajueiro-anãoprecoce - clone CCP-006. Caatinga, v.11, n.1/2, p.11-22, 1998. 